\title{
Seawater Survival of Enteromyxum leei (Myxozoa) Evaluated by In Vitro Viability and In Vivo Infectivity Assays
}

\author{
Hiroshi Yokoyama ${ }^{1 *}$, Masahiro Kageyama ${ }^{1}$, \\ Tetsuya Yanagida ${ }^{2}$ and Kazuo Ogawa ${ }^{1}$ \\ ${ }^{1}$ Department of Aquatic Bioscience, Graduate School of Agricultural and Life Sciences, \\ The University of Tokyo, Tokyo 113-8657, Japan \\ ${ }^{2}$ Department of Parasitology, Asahikawa Medical College, Hokkaido 078-8510, Japan
}

(Received July 6, 2009)

\begin{abstract}
A vital staining assay using Hoechst 33342 and propidium iodide was developed for the determination of viability of Enteromyxum leei (Myxozoa), a causative agent of myxosporean emaciation disease. Using this in vitro viability assay combined with in vivo infectivity test, the survival of developmental stages of $E$. leei in seawater was evaluated. Developmental stages of $E$. leei were freshly isolated from infected tiger puffer Takifugu rubripes and incubated in filtered natural seawater at $20^{\circ} \mathrm{C}$ for 0 , 6,12 and $24 \mathrm{~h}$. The in vitro staining assay showed a time-dependent decrease in viability, and no viable stages were detected at $24 \mathrm{~h}$. In the first trial of in vivo infectivity, naïve tiger puffer were exposed to $E$. leei suspensions which were incubated in seawater for $0-48 \mathrm{~h}$. In the second trial, naïve grass puffer $T$. niphobles were fed $E$. leei incubated for $0-24 \mathrm{~h}$. After rearing for 3-4 weeks, infection with $E$. leei was detected in fish challenged with the parasite incubated for 24 and $6 \mathrm{~h}$ in the first and second trials, respectively. Results of the in vitro and in vivo assays showed that the survival time of developmental stages of $E$. leei in seawater was variable but estimated less than $24 \mathrm{~h}$.
\end{abstract}

Key words: Enteromyxum leei, Myxozoa, Hoechst 33342, propidium iodide, myxosporean emaciation disease, Takifugu rubripes, tiger puffer

Enteromyxum leei is an enteric parasite that causes the myxosporean emaciation disease of cultured marine fishes, in particular tiger puffer Takifugu rubripes in Japan (Tin Tun et al., 2000; Yanagida et al., 2004; Ishimatsu et al., 2007). Recently, the host range of the parasite was extended to other fishes including Japanese flounder Paralichthys olivaceus, red sea bream Pagrus major and spotted knifejaw Oplegnathus punctatus in Japanese aquaculture (Yasuda et al., 2005; Yanagida et al., 2008). Although the life cycle of myxosporeans generally involves the actinosporean stage in the alternate annelid hosts (Yokoyama, 2003), fish-tofish transmission of $E$. leei was experimentally demonstrated (Diamant, 1997; Yasuda et al., 2002). It has been considered that infected fish excretes gut mucosa fragments containing numerous developmental stages of $E$. leei, causing oral transmission to other fish (Diamant, 1997). It is probable that this unique characteristic of the parasite results in such a rapid spread of the disease within/between sea cages. The pre-sporogonic developmental stages of $E$. leei are believed to be infectious to other fish, but the biology of the infective

\footnotetext{
* Corresponding author

E-mail: ayokoh@mail.ecc.u-tokyo.ac.jp
}

stage, e.g., the survival of the parasite in seawater, is poorly understood. The viability of infectious developmental stages is likely to have a considerable impact on the parasite's dispersion in fish farms.

Until now, a reliable method for determining the viability of myxosporeans has not been fully developed. Dye-exclusion assays using eosin, eosin-nigrosin and trypan blue were documented as a viability test for developmental stages of Enteromyxum spp. (Redondo et al., 2003; Yokoyama and Shirakashi, 2007). However, these methods often cause variable and inconsistent results. A dual staining with fluorescein diacetate (FDA) and propidium iodide (PI) was also utilized for assessment of myxosporean and actinosporean viability (Markiw, 1992; Yokoyama et al., 1997). FDA is deacetylated by intracellular esterase to yield green fluorescence in viable cells, while PI permeates only through the membrane of dead cells and emits a red fluorescence. Using the FDA-PI staining, viable (stained green) and non-viable (stained red) cells were distinctly visualized by fluorescent microscopy. However, a problem of relatively rapid fading of green fluorescence by FDA remained to be solved. Another disadvantage of this method is a difficulty in discriminating the developmental stages of $E$. leei from host epithelial 
cells in wet preparation.

The fluorescent dye Hoechst 33342 (HO) penetrates the membrane of both live and dead cells, specifically binds nucleic acid and intercalates into DNA, resulting in emission of bright blue fluorescence by ultraviolet light. HO stain has been commonly used for cell viability in combination with PI (Foglieni et al., 2001; Rowland et al., 2003; Cai et al., 2005). Double staining with $\mathrm{HO}$ and $\mathrm{PI}$ discriminates accurately between live and dead cells because $\mathrm{PI}$ quenches the $\mathrm{HO}$ fluorescence of dead cells (Cai et al., 2005). Our preliminary experiment also revealed that $\mathrm{HO}$ stain allowed distinguishing the developmental stages of $E$. leei from the host cells on the basis of the multinuclear characteristics of the myxosporean plasmodia. The objective of the present study was to develop a vital staining technique with $\mathrm{HO}$ and $\mathrm{PI}$ for determining the viability of $E$. leei, and to evaluate the survival of developmental stages of $E$. leei in seawater using the in vitro viability and in vivo infectivity assays.

\section{Materials and Methods}

\section{Vital staining with $\mathrm{HO}$ and $\mathrm{PI}$}

As a source of $E$. leei material, three experimentally infected tiger puffer (average body length $=8.3 \mathrm{~cm}$, average body weight $=22.4 \mathrm{~g}$ ) were used. Fish were dissected, and the intestinal mucosa was scraped using a sterile razor blade. Developmental stages of $E$. leei were collected in physiological saline, passed through a stainless steel mesh screen ('40 mesh screen' with opening size of $380 \mu \mathrm{m}$, Cell Dissociation Sieve, Sigma) and centrifuged at $365 \times g$ for $10 \mathrm{~min}$. After the supernatant was discarded, the pellet was divided into two parts. One part was suspended in physiological saline, while the other was fixed in $10 \%$ formalin (as a negative control). Working solutions of $\mathrm{HO}(1 \mathrm{~mm}$ dissolved in phosphate buffered saline (PBS), bisbenzimide H33342 trihydrochloride, Sigma) and PI (0.02 $\mathrm{mg} / \mathrm{mL}$ dissolved in PBS, Sigma) were prepared. Twenty five $\mu \mathrm{L}$ of parasite suspension, $25 \mu \mathrm{L}$ of PI solution and $50 \mu \mathrm{L}$ of $\mathrm{HO}$ solution were mixed in a $1.5 \mathrm{~mL}$ microtube and kept in the dark at $5^{\circ} \mathrm{C}$ for $15 \mathrm{~min}$. After a cover slip was placed over a drop of $25 \mu \mathrm{L}$ of the mixture on a glass slide, parasites were observed with an ultraviolet epifluorescent microscope (BX60, Olympus). On the basis of 50 multinuclear developmental stages of $E$. leei, the fluorescence pattern was classified as follows; 1 ) only nuclei showing blue fluorescence (HO-positive, Pl-negative), 2) mixed nuclei showing blue or red fluorescence (HO-positive, PI-positive or negative), 3) only nuclei showing red fluorescence (HO-positive, $\mathrm{PI}$ positive) (Fig. 1).

In vitro viability assay of $\mathrm{E}$. leei incubated in seawater

Developmental stages of $E$. leei were isolated from
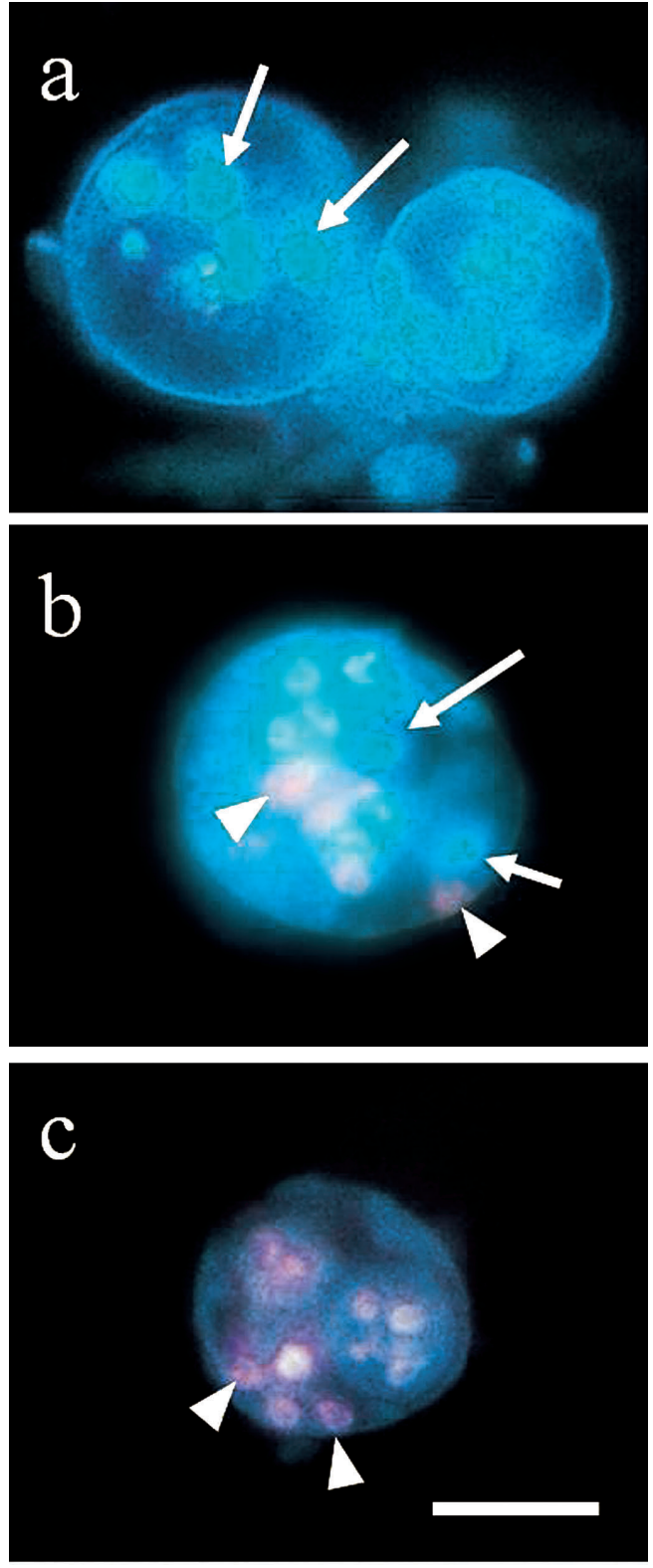

Fig. 1. Three fluorescence patterns of developmental stages of Enteromyxum leei stained with Hoechst 33342 $(\mathrm{HO})$ and propidium iodide $(\mathrm{PI})$ observed under UV light (a: $\mathrm{HO}+, \mathrm{PI}-$; b: $\mathrm{HO}+, \mathrm{PI}+/-$; $\mathbf{c}: \mathrm{HO}+, \mathrm{PI}+$ ). Arrows and arrowheads show HO-positive and PI-positive nuclei, respectively. $\mathrm{Bar}=10 \mu \mathrm{m}$.

the intestinal mucosa of seven experimentally infected tiger puffer (average body length $=8.7 \mathrm{~cm}$, average body weight $=24.2 \mathrm{~g}$ ). After the suspension of $E$. leei was prepared as described above, the parasite material was divided equally into five tubes containing $10 \mathrm{~mL}$ filtered natural seawater (ca. 32\%) supplemented with an antibiotic mixture (100 units $/ \mathrm{mL}$ penicillin $\mathrm{G}, 100 \mu \mathrm{g} / \mathrm{mL}$ streptomycin, $0.25 \mu \mathrm{g} / \mathrm{mL}$ amphotericin B). The five tubes were kept at $20^{\circ} \mathrm{C}$ in the dark. After 0 (positive control), 6, 12 and $24 \mathrm{~h}$, each tube was centrifuged at $365 \times g$ for $10 \mathrm{~min}$. The supernatant was removed, 
and the pellet was resuspended in $1 \mathrm{~mL}$ of PBS. Parasite density was estimated by hemacytometer, followed by the vital staining with $\mathrm{HO}$ and $\mathrm{PI}$. Fluorescence pattern of parasites $(n=50)$ was classified into three groups as described above by fluorescent microscopy. Parasites with only nuclei showing bright blue fluorescence $(\mathrm{HO}+, \mathrm{PI}-)$ were defined as viable, and parasite viability (\%) was estimated on the basis of 50 developmental stages of $E$. leei.

\section{First trial of in vivo infectivity}

Eight experimentally infected tiger puffer (average body weight $=201.3 \mathrm{~g}$ ) were used as 'donor' fish. Developmental stages of $E$. leei were collected from the intestine and suspended in $5 \mathrm{~L}$ of filtered natural seawater (ca. $32 \%$ ) at $20^{\circ} \mathrm{C}$. After 0 (positive control), 6, 12, 24 and $48 \mathrm{~h}$, each $1 \mathrm{~L}$ of the parasite suspension was mixed with $100 \mathrm{~L}$ seawater to prepare as 'infective water'. Each 20 'recipient' naïve tiger puffer (average body weight $=30.2 \mathrm{~g}$ ) were exposed to the 'infective water' in a $100 \mathrm{~L}$ tank (ca. $27^{\circ} \mathrm{C}$ ) provided with aeration. After $6 \mathrm{~h}$ immersion, the fish were split into two tanks (500 $\mathrm{L}$ of water volume, ten fish each) supplied with sand-filtered seawater and reared at $26.8 \pm 4^{\circ} \mathrm{C}$. During the experimental period, all fish were fed a commercial pellet diet at about $0.5 \%$ of body weight/day. Unexposed fish $(n=20)$ were held under equivalent conditions as a negative control. After 3 weeks, all surviving fish were dissected and the gut tissues were excised. Parasites were detected by microscopic observation of Diff-Quik stained imprint slides of the intestinal mucosa, as well as PCR-based assay of $80 \%$ ethanol-fixed gut tissues as described in Yanagida et al. (2005).

Second trial of in vivo infectivity combined with in vitro assay

In the second experiment, in vitro viability and in vivo infectivity assays were used in parallel to evaluate the survivability of $E$. leei at several time points within $24 \mathrm{~h}$ of incubation in seawater. Tissues infected with E. leei were obtained from 20 experimentally infected tiger puffer (average body length $=12.3 \mathrm{~cm}$, average body weight $=47.4 \mathrm{~g}$ ), and developmental stages of the parasite were harvested by filtration through a stainless steel mesh to remove the tissue debris. The parasite suspension was divided equally into four tubes contain- ing $10 \mathrm{~mL}$ of filtered natural seawater with an antibiotic mixture (100 units $/ \mathrm{mL}$ penicillin G, $100 \mu \mathrm{g} / \mathrm{mL}$ streptomycin, $0.25 \mu \mathrm{g} / \mathrm{mL}$ amphotericin B) and kept at $20^{\circ} \mathrm{C}$ in the dark. After 0 (positive control), 6, 12 and $24 \mathrm{~h}$, the parasites were concentrated into $1 \mathrm{~mL}$ of PBS by centrifugation at $365 \times g$ for $10 \mathrm{~min}$. Parasites were enumerated using hematocyte counting chambers, and the parasite viability was determined by the in vitro viability assay as described above.

Naïve grass puffer Takifugu niphobles (average body weight $=2.0 \mathrm{~g}$ ) artificially bred by Fisheries Laboratory of The University of Tokyo were used as recipient fish, as their susceptibility to $E$. leei is similar to tiger puffer (Yokoyama and Shirakashi, 2007). Four groups of 15 grass puffer were kept in $65 \mathrm{~L}$ tanks (55 L of water volume) equipped with a closed re-circulating filtration system. At the same time points of incubation of $E$. leei described above, 15 grass puffer were fed the sub-samples of incubated parasites mixed with $0.5 \mathrm{~g}$ of commercial kneaded feed for eel. As a negative control, 15 grass puffer were fed $0.5 \mathrm{~g}$ of commercial kneaded feed mixed with sterilized distilled water. Subsequently, the experimental fish were reared at a constant temperature of $25^{\circ} \mathrm{C}$. After 4 weeks, infection with $E$. leei was determined by microscopy and PCR as described in the first trial.

\section{Results}

Vital staining with $\mathrm{HO}$ and $\mathrm{PI}$

Developmental stages of freshly obtained $E$. leei exhibited the three patterns of fluorescence; 1) $\mathrm{HO}+, \mathrm{PI}$ -; 2) $\mathrm{HO}+, \mathrm{PI}+/-$; 3) $\mathrm{HO}+, \mathrm{PI}+$, with percentages of $68 \%, 24 \%$ and $8 \%$, respectively (Table 1). For formalin-fixed $E$. leei, the percentages were $0 \%, 10 \%$ and $90 \%$, respectively. Thus, parasites showing $\mathrm{HO}+$ and $\mathrm{PI}$ - were considered viable.

In vitro viability assay

Although no considerable change in the parasite density occurred during the period kept in seawater (1.2-2.1 $\times 10^{5}$ parasite $\left./ \mathrm{mL}\right)$, degeneration of parasites appeared to progress with time (data not shown). In vitro staining assay showed a time-dependent decrease in viability, and no viable stages were observed at $24 \mathrm{~h}$ (Table 2). At the end of the experiment $(24 \mathrm{~h})$, all nuclei of the parasites stained red $(\mathrm{HO}+, \mathrm{PI}+)$.

Table 1. Fluorescence patterns of fresh and fixed Enteromyxum leei by in vitro staining with Hoechst $33342(\mathrm{HO})$ and propidium iodide (PI)

\begin{tabular}{lcccr}
\hline \multirow{2}{*}{$\begin{array}{c}\text { Parasite } \\
\text { condition }\end{array}$} & Parasite density & \multicolumn{3}{c}{ Fluorescence pattern (\%) } \\
\cline { 3 - 5 } (parasites $/ \mathrm{mL})$ & $\mathrm{HO}+, \mathrm{PI}-$ & $\mathrm{HO}+, \mathrm{PI}+/-$ & $\mathrm{HO}+, \mathrm{PI}+$ \\
\hline Fresh & $3.4 \times 10^{5}$ & $68( \pm 6.0)^{*}$ & $24( \pm 5.1)$ & $8( \pm 2.0)$ \\
Formalin-fixed & $2.8 \times 10^{5}$ & $0( \pm 0)$ & $10( \pm 2.5)$ & $90( \pm 2.5)$ \\
\hline
\end{tabular}

* Values in parentheses show the confidence intervals at $95 \%$ in reliability. 
Table 2. Viability of Enteromyxum leei incubated for $0-24 \mathrm{~h}$ in seawater at $20^{\circ} \mathrm{C}$ and evaluated by in vitro staining assay with Hoechst $33342(\mathrm{HO})$ and propidium iodide $(\mathrm{PI})$

\begin{tabular}{cccccc}
\hline \multirow{2}{*}{$\begin{array}{c}\text { Time }(\mathrm{h}) \text { in } \\
\text { seawater }\end{array}$} & $\begin{array}{c}\text { Parasite } \\
\text { density }\end{array}$ & \multirow{2}{*}{$\begin{array}{c}\text { Viability } \\
(\text { parasites } / \mathrm{mL})\end{array}$} & $(\%)$ & \multicolumn{3}{c}{ Fluorescence pattern $(\%)$} \\
\cline { 3 - 6 } & $2.1 \times 10^{5}$ & $30( \pm 5.8)^{*}$ & $30( \pm 5.8)$ & $48( \pm 6.9)$ & $22( \pm 4.8)$ \\
\hline 0 & $1.2 \times 10^{5}$ & $18( \pm 4.1)$ & $18( \pm 4.1)$ & $52( \pm 6.9)$ & $30( \pm 5.8)$ \\
6 & $1.4 \times 10^{5}$ & $6( \pm 1.6)$ & $6( \pm 1.6)$ & $36( \pm 6.4)$ & $58( \pm 6.7)$ \\
12 & $1.3 \times 10^{5}$ & $0( \pm 0)$ & $0( \pm 0)$ & $0( \pm 0)$ & $100( \pm 0)$ \\
24 & &
\end{tabular}

* Values in parentheses show the confidence intervals at $95 \%$ in reliability.

First trial of in vivo infectivity

Differences between the duplicate tanks were not great enough to exclude the possibility that the differences were due to the tank effect (Fisher's exact test, $p$ $<0.05)$. Accordingly, data from the duplicates were pooled for each time point. Fish exposed to freshly collected (non-incubated) E. leei had $15.8 \%$ infection prevalence (Table 3). Prevalence of infection decreased with time in seawater down to $0 \%$ in 12 and $48 \mathrm{~h}$ groups, but $23.5 \%$ of fish were infected in $24 \mathrm{~h}$ group. Negative controls remained uninfected. Although some of the fish died during the experimental period, no disease signs were observed in any of the groups.

Table 3. Infectivity of Enteromyxum leei incubated for $0-48 \mathrm{~h}$ in seawater and evaluated by in vivo infection experiment using tiger puffer

\begin{tabular}{cc}
\hline Time $(\mathrm{h})$ in seawater & Prevalence of infection $(\%)$ \\
\hline 0 & $15.8(19)^{*}$ \\
6 & $11.1(18)$ \\
12 & $0(17)$ \\
24 & $23.5(17)$ \\
48 & $0(20)$ \\
\hline
\end{tabular}

* Number in parenthesis is the number of fish examined.

Second trial of in vivo infectivity combined with in vitro viability assay

The parasite density was $1.3 \times 10^{6}$ parasites $/ \mathrm{mL}$ at the beginning and decreased gradually with time (Table 4). Although $52 \%$ of parasites were viable at the initial time, viability rapidly declined to $4 \%$ at $6 \mathrm{~h}$. Prevalence of infection in grass puffer fed with fresh (non-preserved) and $6 \mathrm{~h}$ preserved $E$. leei was $100 \%$ and $60 \%$, respectively (Table 4 ). In 12 and $24 \mathrm{~h}$ preserved groups, neither viable stages nor infection were observed in in vitro and in vivo assays, respectively. Negative controls remained uninfected.

\section{Discussion}

The present study indicates that a double staining with $\mathrm{HO}$ and $\mathrm{PI}$ is a possible indicator of the viability of developmental stages of $E$. leei. It may be confusing that some of parasites have exhibited the ambiguous fluorescence pattern $(\mathrm{HO}+, \mathrm{PI}+/-)$. However, the occurrence of this pattern in formalin-killed parasites demonstrates that $\mathrm{HO}+, \mathrm{PI}+/-E$. leei are non-viable. Additionally, in the second infectivity trial, regardless of a moderate percentage $(32 \%)$ of this fluorescence pattern in $12 \mathrm{~h}$ incubated parasites, infection did not occur in the parallel exposure group. Thus, it seems to be reasonable to conclude that only $E$. leei exhibiting $\mathrm{HO}+$ and $\mathrm{PI}-$ are considered viable and infective. Results of the present study also indicate that 'viability' by in vitro vital staining corresponds well to 'infectivity' evaluated by the in vivo experiment as shown in Table 4 . An in vitro viability assay would be valuable for the studies on parasite biology and drug sensitivity tests against E. leei. Also, if the dyes could penetrate the spore valves of myxosporean, the present staining technique would be likely useful for other myxosporean species.

Variable results were obtained in the initial viability of $E$. leei and the prevalence of infection among the different experiments in the current study. Even though the parasite was freshly collected, some stages might have been deteriorated by host's digestive enzymes or by the process of harvesting, possibly causing the wide

Table 4. Viability of Enteromyxum leei incubated for $0-24 \mathrm{~h}$ in seawater at $20^{\circ} \mathrm{C}$ by in vitro staining assay using $\mathrm{Hoechst} 33342(\mathrm{HO})$ and propidium iodide (PI), and the infectivity of the parasite at the same time point by in vivo infection experiment using grass puffer

\begin{tabular}{ccccccr}
\hline \multirow{2}{*}{$\begin{array}{c}\text { Time }(\mathrm{h}) \text { in } \\
\text { seawater }\end{array}$} & $\begin{array}{c}\text { Parasite density } \\
\text { (parasites } / \mathrm{mL})\end{array}$ & Viability $(\%)$ & $\mathrm{HO}+, \mathrm{PI}-$ & $\mathrm{HO}+, \mathrm{PI}+/-$ & $\mathrm{HO}+, \mathrm{PI}+$ & $\begin{array}{c}\text { Prevalence of } \\
\text { infection }(\%)\end{array}$ \\
\hline 0 & $1.3 \times 10^{6}$ & $52( \pm 6.9)^{*}$ & $52( \pm 6.9)$ & $44( \pm 6.8)$ & $4( \pm 1.1)$ & 100 \\
6 & $9.1 \times 10^{5}$ & $4( \pm 1.1)$ & $4( \pm 1.1)$ & $46( \pm 6.9)$ & $50( \pm 6.9)$ & 60 \\
12 & $5.9 \times 10^{5}$ & $0( \pm 0)$ & $0( \pm 0)$ & $32( \pm 6.0)$ & $68( \pm 6.0)$ & 0 \\
24 & $3.3 \times 10^{5}$ & $0( \pm 0)$ & $0( \pm 0)$ & $0( \pm 0)$ & $100( \pm 0)$ & 0 \\
\hline
\end{tabular}

* Values in parentheses show the confidence intervals at $95 \%$ in reliability. 
variation in initial viability of $E$. leei. It suggests that the same lot of $E$. leei infected tissue should be used for in vitro and in vivo studies. Prevalence of infection with $E$. leei in recipient fish varied between the two trials in this study. It is unknown whether this variation was caused by differences in the initial condition of parasite, because the viability of $E$. leei was not determined in the first trial. Alternatively, it may be due to the difference in challenge method (immersion vs per os for the first and second trials, respectively). It is likely that recipient fish given per os would ingest actively the parasite, resulting in more efficient transmission of $E$. leei than the immersion method. Redondo et al. (2002) also found that oral ingestion of infected intestine is the most effective for transmission of E. scophthalmi, compared with cohabitation with infected fish or waterborne exposure to the effluent of a tank containing infected fish. To standardize the infection experiment of $E$. leei, further studies are required on the collection of parasite, parasite dose and route of infection.

Overall results of the present study seem to indicate that the survival time of $E$. leei is less than $24 \mathrm{~h}$ at $20^{\circ} \mathrm{C}$ in the marine environment, though it is possible that the survivability is influenced by water temperature. Temperature of parasite incubation was set only at $20^{\circ} \mathrm{C}$ in the present study, because occurrence of the disease was usually found around $20^{\circ} \mathrm{C}$ in fish farms, and also because $20^{\circ} \mathrm{C}$ seemed to be the appropriate temperature for development of E. leei (Yanagida et al., 2006). This estimation is comparable to the result of Redondo et al. (2003) who reported that developmental stages of E. scophthalmi remained viable in vitro for approximately one day in seawater at $20^{\circ} \mathrm{C}$, though they did not investigate the infectivity of incubated parasites by in vivo infection. Nevertheless, in the present study, $23.5 \%$ of fish exposed to $24 \mathrm{~h}$ incubated $E$. leei were infected in the first trial, while in the second trial no infection was observed in the equivalent group. This difference may be explained by the difference in preparation methods between the two trials. In the second trial, parasite was carefully purified using filtration with stainless steel mesh to remove the host tissue debris, but such a treatment was not done in the first trial. The mucosal remnants derived from the infected intestine might have protected the developmental stages of E. leei from osmotic shock (Diamant, 1997; Redondo et al., 2002). However, the data from the first trial may reflect the actual situation in fish farms. Indeed, according to empirical observations, floating mucosal fragments possibly harboring $E$. leei have been frequently found on the water surface of infected cages/tanks.

As a management strategy for preventing the spread of $E$. leei, it is recommended that naïve fish stocks should be kept from infected fish cages as far as possible (theoretically, more than a distance that $E$. leei migrates within $24 \mathrm{~h}$ ). However, it is difficult to determine the distance required between neighboring sea cages, because dispersal of the non-motile developmental stages of $E$. leei could be strongly influenced by water currents. Chambers and Ernst (2005) investigated the influence of tidal currents on dispersal of eggs of the monogenean Benedenia seriolae in a large-scale farm of kingfish Seriola lalandi located in South Australia. Parasite eggs dispersed only at sites along the tidal current, rather than across the current direction. Also, eggs were found to reach a cage placed more than $8 \mathrm{~km}$ from the source farm. It would be difficult to apply their data directly to the Japanese farm condition, because fish farms in Japan are densely located within bays where the tidal current is complicated. Evacuation of sea cages to offshore area with faster water flow may be practiced so that the parasite density can be diluted, possibly decreasing the chance of ingestion by susceptible fish. In case of land-based culture farms, increased exchange rates of rearing water would help to flush the waterborne parasite out of fish tank.

\section{Acknowledgements}

We would like to thank Mr. Yoshinori Nomura of the Kumamoto Prefectural Fisheries Research Center for his supports in our experiment, Miyazaki Prefectural Fisheries Experimental Station for providing the parasite materials and Fisheries Laboratory of the University of Tokyo for providing the experimental fish.

\section{References}

Cai, K., J. Yang, M. Guan, W. Ji, Y. Li and W. Rens (2005): Single UV excitation of Hoechst 33342 and propidium iodide for viability assessment of rhesus monkey spermatozoa using flow cytometry. Arch. Androl., 51, 371-383.

Chambers, C. B. and I. Ernst (2005): Dispersal of the skin fluke Benedenia seriolae (Monogenea: Capsalidae) by tidal currents and implications for sea-cage farming of Seriola spp. Aquaculture, 250, 60-69.

Diamant, A. (1997): Fish-to-fish transmission of a marine myxosporean. Dis. Aquat. Org., 30, 99-105.

Foglieni, C., C. Meoni and A. M. Davalli (2001): Fluorescent dyes for cell viability: an application on prefixed conditions. Histochem. Cell Biol., 115, 223-229.

Ishimatsu, A., M. Hayashi, M. Nakane and M. Sameshima (2007): Pathophysiology of cultured tiger puffer Takifugu rubripes suffering from the myxosporean emaciation disease. Fish Pathol., 42, 211-217.

Markiw, M. E. (1992): Experimentally induced whirling disease II. Determination of longevity of the infective triactinomyxon stage of Myxobolus cerebralis by vital staining. $J$. Aquat. Anim. Health, 4, 44-47.

Redondo, M. J., O. Palenzuela, A. Riaza, A. Macias and P. Alvarez-Pellitero (2002): Experimental transmission of Enteromyxum scophthalmi (Myxozoa), an enteric parasite of turbot Scophthalmus maximus. J. Parasitol., 88, $482-488$.

Redondo, M. J., O. Palenzuela and P. Alvarez-Pellitero (2003): 
In vitro studies on viability and proliferation of Enteromyxum scophthalmi (Myxozoa), an enteric parasite of cultured turbot Scophthalmus maximus. Dis. Aquat. Org., 55, 133-144.

Rowland, S. C., J. D. Jacobson, W. C. Patton, A. King and P. J. Chan (2003): Dual fluorescence analysis of DNA apoptosis in sperm. Am. J. Obstet. Gynecol., 188, 1156-1157.

Tin Tun, H. Yokoyama, K. Ogawa and H. Wakabayashi (2000): Myxosporeans and their hyperparasitic microsporeans in the intestine of emaciated tiger puffer. Fish Pathol., 35, $145-156$

Yanagida, T., Y. Nomura, T. Kimura, Y. Fukuda, H. Yokoyama and K. Ogawa (2004): Molecular and morphological redescriptions of enteric myxozoans, Enteromyxum leei (formerly Myxidium sp. TP) and Enteromyxum fugu comb. n. (syn. Myxidium fugu) from cultured tiger puffer. Fish Pathol., 39, 137-143.

Yanagida, T., M. A. Freeman, Y. Nomura, I. Takami, Y. Sugihara, H. Yokoyama and K. Ogawa (2005): Development of a PCR-based method for the detection of enteric myxozoans causing the emaciation disease of cultured tiger puffer. Fish Pathol., 40, 23-28.

Yanagida, T., M. Sameshima, H. Nasu, H. Yokoyama and K. Ogawa (2006): Temperature effects on the development of Enteromyxum spp. (Myxozoa) in experimentally infected tiger puffer, Takifugu rubripes (Temminck \& Schlegel). J.
Fish Dis., 29, 561-567.

Yanagida, T., O. Palenzuela, T. Hirae, S. Tanaka, H. Yokoyama and K. Ogawa (2008): Myxosporean emaciation disease of cultured red sea bream Pagrus major and spotted knifejaw Oplegnathus punctatus. Fish Pathol., 43, 45-48.

Yasuda, H., T. Ooyama, K. Iwata, Tin Tun, H. Yokoyama and K. Ogawa (2002): Fish-to-fish transmission of Myxidium spp. (Myxozoa) in cultured tiger puffer suffering from emaciation disease. Fish Pathol., 37, 29-33.

Yasuda, H., T. Ooyama, A. Nakamura, K. Iwata, O. Palenzuela and $\mathrm{H}$. Yokoyama (2005): Occurrence of the myxosporean emaciation disease caused by Enteromyxum leei in cultured Japanese flounder Paralichthys olivaceus. Fish Pathol., 40, 175-180.

Yokoyama, H. (2003): A review: gaps in our knowledge on myxozoan parasites of fishes. Fish Pathol., 38, 125-136.

Yokoyama, H., T. Danjo, K. Ogawa and H. Wakabayashi (1997): A vital staining technique with fluorescein diacetate (FDA) and propidium iodide (PI) for the determination of viability of myxosporean and actinosporean spores. $J$. Fish Dis., 20, 281-286.

Yokoyama, H. and S. Shirakashi (2007): Evaluation of hyposalinity treatment on infection with Enteromyxum leei (Myxozoa) using anemonefish Amphiprion spp. as experimental host. Bull. Eur. Ass. Fish Pathol., 27, 74-78. 